\title{
VEGF Targeting Agents in Ovarian Cancer
}

\author{
Seiji Mabuchi, Atsuko Wakabayashi and Tadashi Kimura \\ Department of Obstetrics and Gynecology, Osaka University \\ Japan
}

\section{Introduction}

Angiogenesis, the formation of new blood vessels, is a critical component in the growth and metastasis of cancers and has been recognized as an attractive target for anticancer therapy (Ferrara, 2002). Among the pro-angiogenic factors, vascular endothelial growth factor (VEGF) is recognized as the predominant mediator of angiogenesis in tumor cells (Ferrara \& Kerbel, 2005). As VEGF is overexpressed in most ovarian cancers, the VEGF pathway is a promising target for anti-angiogenic therapy against ovarian cancer (Burger, 2011).

Recent increases in our understanding of the molecular pathways that control tumor angiogenesis have led to the development of novel VEGF-targeting agents for the treatment of ovarian cancer (Burger, 2011). In addition to inhibiting neo-vascularization, antiangiogenic agents are also believed to normalize intratumoral blood vessels. Intratumoral vessels are hyperpermeable, leading to interstitial hypertension and impaired perfusion in tumors. Normalization of the tumor vasculature results in a reduction in interstitial pressure and the improved delivery of oxygen, nutrients, and cytotoxic agents (Ferrara, 2002).

Many of these agents have been evaluated in clinical trials, and some of them have shown promising clinical activity against ovarian cancer (Burger, 2011). In this article, we review the emerging VEGF-targeting strategies for treating ovarian cancer and provide information about the latest clinical studies of VEGF-targeting agents that have been employed as treatments for ovarian cancer.

\section{Angiogenesis overview}

Angiogenesis is the process by which new blood vessels grow from the existing vasculature. A tumor is unable to grow beyond $2 \mathrm{~mm}$ diameter without neoangiogenesis (Carmeliet, 2000), thus, angiogenesis plays an essential role in tumor growth, invasion, and metastasis (Carmeliet, 2000; Kerbel, 1991). Angiogenesis is tightly regulated by balancing pro- and antiangiogenic factors. The transition of a tumor from "avascular phase" to "vascular phase" is termed "angiogenic switch". This switch is believed to be stimulated by an increase in expression of pro-angiogenic factors. A variety of pro-angiogenic factors have been identified and recognized as potential targets of antiangiogenic therapy (Ferrara \& Kerbel, 2005). Vascular endothelial cell growth factor (VEGF), one of the key mediators of angiogenesis, promotes the proliferation, survival, and migration of endothelial cells and is essential for blood vessel formation (Ferrara \& Kerbel, 2005). VEGF can also affect new vessel formation in tumors by acting as a chemoattractant for bone marrow-derived progenitor cells (Rafii et al., 2002). The major physiological stimulus for VEGF expression is 
hypoxia, which commonly develops within tumors when cancer cell proliferation exceeds the rate of blood vessel formation. Hypoxia inducible factor- $1 \alpha$ (HIF-1 $\alpha)$, a transcriptional activator that acts as a central regulator of oxygen homeostasis, regulates the expression of VEGF and promotes angiogenesis, which is essential for fulfilling the metabolic requirements of tumor growth (Forsythe et al., 1996).

\section{Vascular endothelial growth factor (VEGF): Structure and function}

VEGF (also referred to as VEGF-A) is a dimeric protein that has been shown to stimulate angiogenesis. As it also enhances vascular permeability, VEGF is also recognized as vascular permeability factor (VPF) (Ferrara \& Kerbel, 2005).

VEGF is a member of the VEGF/PDGF gene family. Other members of this family include VEGF-B, VEGF-C, VEGF-D, PDGF, and PIGF (Ferrara \& Kerbel, 2005). VEGF exerts its biological effects by interacting with the VEGF receptors (VEGFR) present on the cell surface (Figure 1). These transmembrane receptors include VEGFR-1 (also known as Flt-1) and VEGFR-2 (Flk-1), which are predominantly expressed on vascular endothelial cells. A third receptor, VEGFR-3 (Flt-4), is mainly involved in the regulation of lymphatic systems (Karkkainen et al., 2001). The binding of VEGF to its receptor causes the dimerization and phosphorylation of intracellular receptor kinases, which in turn activates a cascade of downstream signals responsible for tumor angiogenesis (Ferrara \& Kerbel, 2005).

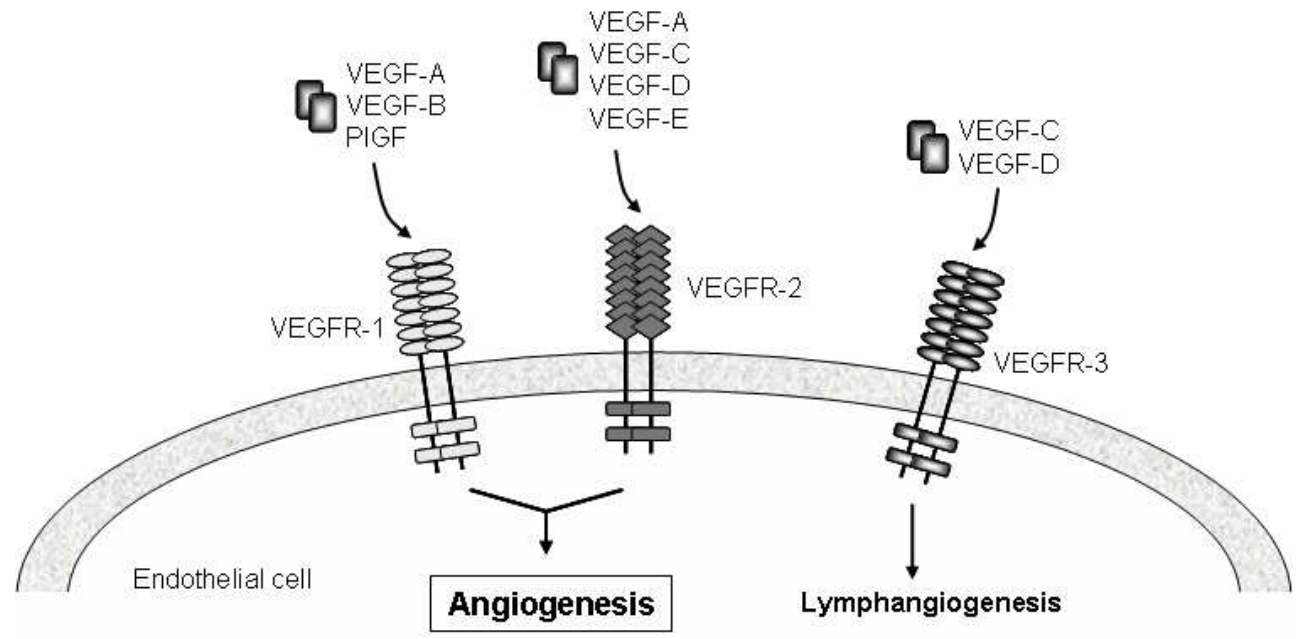

Fig. 1. VEGF signaling.

\section{Role of VEGF in epithelial ovarian cancer: Preclinical findings}

\subsection{VEGF expression in epithelial ovarian cancer}

VEGF expression in epithelial ovarian cancer has been intensively examined (Wong et al., 2003; Yamamoto et al., 1997; Brustmann, 2004; Mabuchi et al., 2010b). It has been generally accepted that VEGF expression is greater in ovarian cancers than in normal ovarian tissue or benign ovarian neoplasm. According to previous reports, in which common histological 
subtypes such as serous adenocarcinoma or endometrioid adenocarcinoma were investigated, the expression rate of VEGF was approximately 90\% (Wong et al., 2003; Yamamoto et al., 1997; Brustmann, 2004). In a recent report about clear cell carcinoma of the ovary, strong VEGF expression was observed in $86 \%$ of cases (Mabuchi et al., 2010b). These results suggest that most epithelial ovarian cancers are dependent on VEGF for tumor progression, and hence, are candidates for VEGF targeting therapy.

\subsection{VEGF expression and patient prognosis}

In patients with ovarian cancer, high serum VEGF levels are an independent risk factor for advanced stage and decreased survival (Mabuchi et al., 2010b; Cooper et al., 2002; Li et al., 2004; Hefler et al., 2006). Moreover, previous immunohistochemical analyses have suggested that VEGF expression in ovarian cancer specimens is also associated with poor patient prognosis, advanced stage, and short survival (Mabuchi et al., 2010b; Cooper et al., 2002; Li et al., 2004; Hefler et al., 2006). For example, in a recent investigation of ovarian clear cell carcinomas (Mabuchi et al., 2010b), patients whose tumor showed strong immunoreactivity displayed significantly shorter survival than those with weak immunoreactivity for VEGF (mean: 60 months vs. 40 months, respectively). The association observed between VEGF expression and clinical outcome in ovarian cancer patients makes the VEGF pathway an attractive therapeutic target in this patient group.

\subsection{VEGF expression and ascites formation}

The effect of VEGF on vascular permeability is believed to be crucial for malignant ascites formation (Senger et al., 1983; Zhang et al., 2002). In patients with ovarian cancer, high serum VEGF levels was reported to be an independent risk factor for developing ascites formation (Cooper et al., 2002; Li et al., 2004; Hefler et al., 2006). In an in vivo investigation using an intraperitoneal ovarian cancer model, VEGF inhibition resulted in the complete inhibition of ascites formation (Mesiano et al., 1998; Mabuchi et al., 2008). Since patients with advanced or recurrent ovarian cancer frequently suffer from malignant ascites and require paracentesis for symptomatic relief, the ability of VEGF-targeting agents to inhibit ascites formation makes them attractive candidate treatments for ovarian cancer (Numnum et al., 2006).

\subsection{VEGF expression and chemoresistance}

It has been reported that chemoresistant tumors display greater VEGF expression than chemosensitive tumors (Mabuchi et al., 2010b; Schönau et al., 2007). For example, 5fluorouracil-resistant colon adenocarcinoma subclones were found to display increased VEGF expression and enhanced pro-angiogenic activity compared to the corresponding primary adenocarcinoma cells (Schönau et al., 2007). Moreover, cisplatin-refractory ovarian cancer cell lines exhibit higher VEGF expression than their parental cisplatin-sensitive cell lines (Mabuchi et al., 2010b). As VEGF increases vascular permeability, which leads to interstitial hypertension and the impaired delivery of cytotoxic agents to tumors; theoretically, increased VEGF production in chemoresistant tumors might further limit the efficacy of chemotherapy (Gerber \& Ferrara, 2005). Therefore, VEGF inhibition is a reasonable treatment strategy for overcoming chemoresistance or enhancing the sensitivity of ovarian cancer to chemotherapeutic agents. 


\subsection{VEGF receptor expression in epithelial ovarian cancer}

VEGFR are predominantly expressed on vascular endothelial cells. However, recent reports have suggested that VEGFR are also expressed by some tumor cells including ovarian cancer cells (Sood et al., 2001; Spannuth et al., 2009). In a study by Spannuth et al, in situ hybridization revealed that VEGFR-1 and VEGFR-2 expression was observed in $85 \%$ and $15 \%$ of human ovarian cancer specimens, respectively. Moreover, using the ovarian cancer cell lines, the authors showed that functionally active VEGFR is present on most ovarian cancer cells (Spannuth et al., 2009). Although the biological role of the VEGFR expressed on tumor cells remains unclear, they might represent an additional target of ovarian cancer therapy.

\section{VEGF targeting agents}

It is generally accepted that, unlike normal vasculature, the intratumoral vessels produced by VEGF-mediated angiogenesis are hyperpermeable, leading to increased interstitial fluid pressure and the impaired perfusion of oxygen and cytotoxic agents into tumors. The resultant hypoxic conditions in tumor cells further increase the expression of VEGF and limit the efficacy of chemotherapy and radiotherapy (Gerber \& Ferrara, 2005). Theoretically, the inhibition of VEGF by VEGF-targeting agents should inhibit neo-vascularization and "normalize" poorly formed, leaky intratumoral blood vessels. This could lead to the improved delivery of cytotoxic agents and oxygen to tumors (Gerber \& Ferrara, 2005).

There are two major strategies used to inhibit the VEGF pathway in cancer therapy (Spannuth et al., 2008). One is the inhibition of the VEGF ligand with antibodies or soluble receptors, and the other is the inhibition of the VEGF receptor with tyrosine kinase inhibitors (TKI) or receptor antibodies (Figure 2). Various VEGF-targeting agents have been identified and are currently being evaluated clinically or preclinically. Of these, bevacizumab, aflibercept, and several TKI are currently being evaluated in phase III clinical trials for the treatment of epithelial ovarian cancer (Table 1-2).

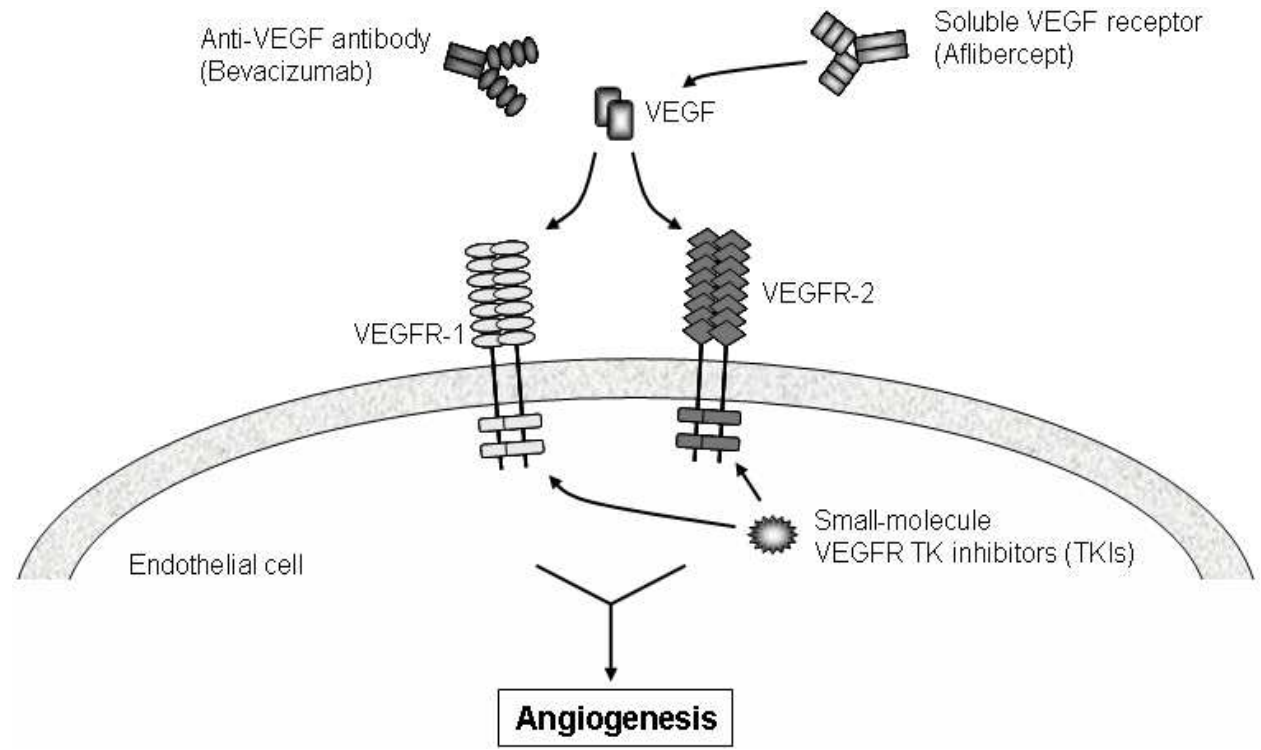

Fig. 2. Strategy to inhibit VEGF signaling 


\section{Therapeutic potential of VEGF targeted agents in ovarian cancer: Preclinical findings}

Among the VEGF-targeting agents including bevacizumab, aflibercept, and TKI, bevacizumab has been used most commonly for the treatment of ovarian cancer in the clinical setting. Thus, we herein provide information regarding the preclinical activity of bevacizumab in ovarian cancer.

\subsection{Monotherapy}

Preclinical in vivo studies have demonstrated that inhibiting VEGF activity using a murine monoclonal antibody to human VEGF (A4.6.1) significantly inhibited the growth of subcutaneously inoculated ovarian tumors. Moreover, in mice carrying intraperitoneal tumors, treatment with A4.6.1 completely inhibited ascites production (Mesiano et al., 1998). Bevacizumab is the humanized form of A4.6.1, which was developed in 1997 (Presta et al., 1997). In a preclinical investigation, treatment with bevacizumab significantly inhibited the growth of intraperitoneally inoculated serous ovarian cancer. In addition, bevacizumab treatment significantly inhibited ascites production and prolonged survival of the mice (Mabuchi et al., 2008).

The single agent activity of bevacizumab on chemoresistant ovarian cancer has also been evaluated preclinically. According to a recent report, the growth inhibitory effect of bevaciumab on cisplatin-resistant ovarian cancer was similar to the effect of bevacizumab on cisplatin-sensitive ovarian cancer (Mabuchi et al., 2010b). Collectively, these results suggest that both platinum-sensitive and platinum-resistant ovarian cancer are the candidates for VEGF-targeting therapy.

\subsection{Combination therapy}

Not only to inhibit neo-vascularization, VEGF-targeted agents are believed to normalize intra-tumoral blood vessels and improved delivery of oxygen, nutrients, and cytotoxic agents (Gerber \& Ferrara, 2005; Jain, 2005). Thus, theoretically, VEGF-targeting agents should be efficacious in combination with chemotherapy.

In a mouse model of ovarian cancer, treatment with bevacizumab in combination with paclitaxel significantly reduced tumor growth compared with paclitaxel alone $(83.3 \%$ reduction in the combination arm versus $58.5 \%$ reduction in the paclitaxel alone arm) and resulted in the complete inhibition of ascites formation (Hu et al., 2002). Similarly, treatment with bevacizumab in combination with cisplatin significantly reduced tumor growth and ascites formation compared with cisplatin therapy alone (Mabuchi et al., 2008).

\subsection{Maintenance therapy}

There is a strong rationale for using angiogenesis targeted agents in the maintenance therapy setting. Since it has been reported that tumors require a vascular blood supply to grow beyond $2 \mathrm{~mm}$ (Gimbrone et al., 1972), any subclinical ovarian tumors that are present after a complete clinical response to first-line chemotherapy should require angiogenesis for their continued proliferation, invasion, and metastasis. Thus, VEGF-targeting maintenance therapy after standard primary treatment might be beneficial for patients with ovarian cancer. 
The effect of VEGF-targeting agent as a maintenance therapy has been investigated in an in vivo ovarian cancer model (Mabuchi et al., 2008). In this investigation, athymic mice were intraperitoneally inoculated with serous ovarian cancer cells. When bevacizumab was used as a maintenance treatment after a complete clinical response to front-line chemotherapy had been obtained, bevacizumab significantly inhibited the recurrence of ovarian cancer and prolonged the survival of the mice (Mabuchi et al., 2008). This is the only preclinical report in which a survival benefit was derived from the use of a VEGF-targeting agent in the setting of maintenance therapy.

\section{VEGF targeting agents in ovarian cancer: A clinical trial review}

\subsection{Bevacizumab}

To date, bevacizumab, a recombinant human monoclonal antibody to the VEGF ligand, is the most studied VEGF-targeting agent in patients with ovarian cancer (Eskander \& Randall, 2011).

\subsubsection{Bevacizumab in the setting of front-line, maintenance, or salvage therapy}

The clinical activity of bevacizumab as a single agent has been prospectively examined in two phase II trials involving patients with recurrent ovarian cancer (Cannistra et al., 2007; Burger et al., 2007). The gynecologic oncology group (GOG) evaluated the efficacy of bevacizumab in a phase II clinical trial involving 62 patients with recurrent ovarian cancer (GOG 170-D). Of the patients enrolled, 3 patients showed a complete response, and 4 patients demonstrated a partial response, giving an overall response rate of $18 \%$ and a median response duration of 10.25 months. Importantly, an additional 34 patients (55\%) showed disease stabilization (Burger et al., 2007). Canninstra et al. also investigated the activity of single agent bevacizumab in 44 patients with platinum-resistant, heavily pretreated ovarian cancer. Of the 44 patients, according to the RECIST guidelines, there were no complete responders, but 7 partial responders were observed. The median duration of the response was 4.3 months (Cannistra et al., 2007).

The effect of bevacizumab has also been examined in the setting of combination therapy in two phase II studies. Garcia et al. evaluated the activity of a combination of bevacizumab and oral cyclophosphamide in patients with recurrent ovarian cancer. Of the 70 patients enrolled, 17 patients $(24 \%)$ demonstrated a partial response, and 44 patients (63\%) showed disease stabilization (Garcia et al., 2008). Penson et al. recently reported on the efficacy of bevacizumab in combination with carboplatin and paclitaxel as a first-line chemotherapy for patients with advanced Mullerian tumors, most of which $(73 \%)$ were ovarian cancers. Of a total of 28 patients with measurable disease, 11 patients (39\%) demonstrated a complete response, and 10 patients (36\%) showed a partial response (Penson et al., 2010).

The evidence of clinical activity found in these phase II studies has led to the development of phase III trials examining the use of bevacizumab for the treatment of ovarian cancer (Teoh \& Secord, 2011; Burger, 2011) (Table 1).

The efficacy of Bevacizumab in combination with carboplatin and paclitaxel as a primary treatment is being evaluated in three phase III trials. The first is a three-arm placebocontrolled trial, GOG 218 (NCT00262847): a 3-armed trial designed to investigate the clinical benefit of adding bevacizumab to front-line carboplatin-paclitaxel chemotherapy, as well as the benefit of bevacizumab maintenance therapy in patients with advanced stage epithelial 
ovarian, primary peritoneal, or fallopian tube cancer (Figure 3). After a median follow-up period of 17.4 months, the preliminary results from 1873 patients were presented at the 2010 meeting of the American Society of Clinical Oncology (ASCO) (Burger et al., 2010). The patients who were treated with concurrent or maintenance bevacizumab showed significantly longer PFS than the standard chemotherapy arm (14.1 months versus 10.3 months; hazard ratio, $0.717 ; 95 \%$ confidence interval, $0.625-0.824 ; \mathrm{p}<0.0001)$. No significant difference in PFS was observed between the patients treated with concurrent bevacizumab and those treated with standard chemotherapy (11.2 months versus 10.3 months; HR, 0.908; 95\% CI, 0.759-1.040; $\mathrm{p}=0.008$ ). The OS data were not mature at the time of the presentation due to the cohort suffering a mortality rate of $24 \%$.

\begin{tabular}{|c|c|c|c|c|}
\hline Study & Setting & Trial design & Status & Outcome \\
\hline GOG 218 & $\begin{array}{l}\text { First-line } \\
\text { adjuvant }\end{array}$ & $\begin{array}{l}\text { Arm 1: CT } \\
\text { Arm 2: CT+Bev } \\
\text { Arm 3: CT+Bev+maintenance Bev }\end{array}$ & $\begin{array}{l}\text { Completed } \\
\text { accrual }\end{array}$ & $\begin{array}{l}\text { Favoring } \\
\text { Arm 3; } \\
\text { HR 0.717; } \\
\text { p<0.0001. }\end{array}$ \\
\hline ICON-7 & $\begin{array}{l}\text { First-line } \\
\text { adjuvant }\end{array}$ & $\begin{array}{l}\text { Arm 1: CT } \\
\text { Arm 2: CT+Bev+maintenance Bev }\end{array}$ & $\begin{array}{l}\text { Completed } \\
\text { accrual }\end{array}$ & $\begin{array}{l}\text { Favoring } \\
\text { arm 2; } \\
\text { HR 0.81; } \\
\text { p<0.0041. }\end{array}$ \\
\hline GOG 252 & $\begin{array}{l}\text { First-line } \\
\text { adjuvant }\end{array}$ & $\begin{aligned} \text { Arm 1: } & \text { PTX (iv, d1, 8, 15)+ } \\
& \text { CBDCA (iv,d1)+ Bev+ } \\
& \text { maintenance Bev } \\
\text { Arm 2: } & \text { PTX (iv, d1, 8, 15)+ } \\
& \text { CBDCA (ip, d1)+Bev+ } \\
& \text { maintenance Bev } \\
\text { Arm 3: } & \text { PTX (iv,d1)+ PTX (ip, d8)+ } \\
& \text { CDDP (ip, d2)+ } \\
& \text { Bev+maintenance Bev }\end{aligned}$ & $\begin{array}{l}\text { Open to } \\
\text { accrual }\end{array}$ & \\
\hline GOG 213 & Recurrent & $\begin{array}{l}\text { Arm 1: CT } \\
\text { Arm 2: CT+Bev+maintenance Bev }\end{array}$ & $\begin{array}{l}\text { Open to } \\
\text { accrual }\end{array}$ & \\
\hline OCEANS & Recurrent & $\begin{array}{l}\text { Arm 1: CG } \\
\text { Arm 2: CG+Bev+maintenance Bev }\end{array}$ & $\begin{array}{l}\text { Completed } \\
\text { accrual }\end{array}$ & $\begin{array}{l}\text { Results not } \\
\text { yet } \\
\text { available }\end{array}$ \\
\hline AURELIA & Recurrent & $\begin{array}{l}\text { Arm 1: PTX, Topo, or PLD } \\
\text { Arm 2: PTX, Topo, or PLD+Bev }\end{array}$ & $\begin{array}{l}\text { Open to } \\
\text { accrual }\end{array}$ & \\
\hline
\end{tabular}

Table 1. Summary of randomized controlled trials evaluating bevacizumab in ovarian cancer. CT, carboplatin plus paclitaxel; CG, carboplatin plus gemcitabine, Bev, bevacizumab, PTX, paclitaxel; CBDCA, carboplatin; CDDP, cisplatin; Topo, topotecan; PLD, liposomal doxorubicin; HR, hazard ratio. 


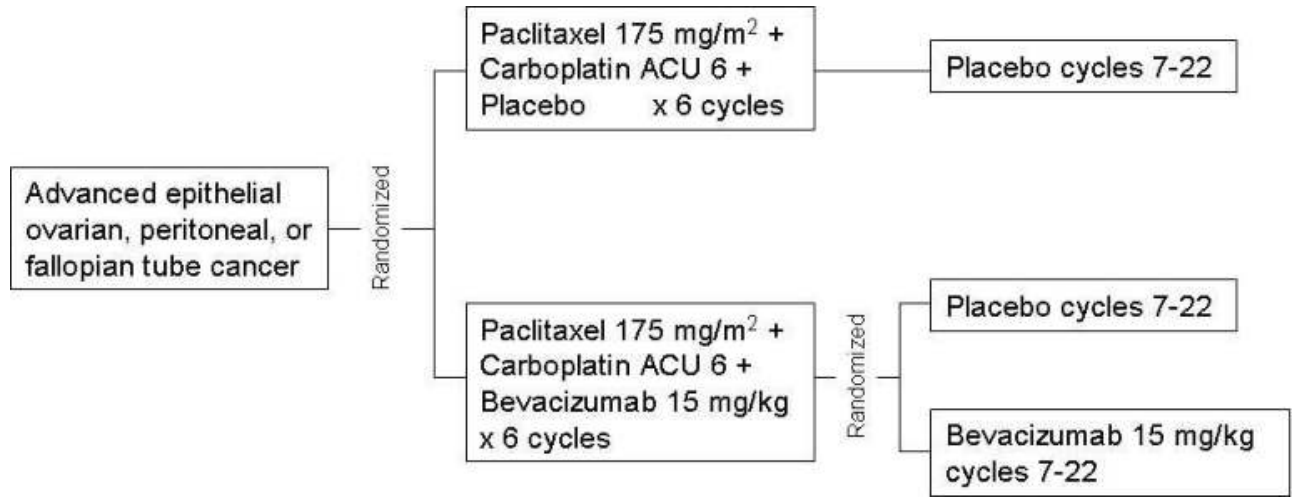

Fig. 3. GOG 218 schema.

The second study is a non-placebo-controlled trial organized by the International Collaborative Ovarian Neoplasm trial, ICON7 (NCT00483782). This study is 2-armed trial designed to compare carboplatin-paclitaxel with bevacizumab plus carboplatin-paclitaxel followed by maintenance bevacizumab therapy in patients with stage IIB-IV or early-stage high-risk ovarian (stage I-Ila with grade 3 or clear cell histology), primary peritoneal, or fallopian tube cancer (Figure 4). Data from the 1528 patients enrolled in this trial were presented at European Society of Medical Oncology meeting (ESMO) in 2010 (Perren et al 2010). The patients that were treated with concurrent and maintenance bevacizumab had a median PFS of 19 months, which was longer than the 17.3 months observed in the patients treated with chemotherapy alone (HR, 0.81; 95\% CI, 0.70-0.94; $\mathrm{p}<0.0041)$. The result of interim analysis presented at the 2011 meeting of the ASCO also showed the superiority of the concurrent and maintenance bevacizumab compared to the standard chemotherapy (median PFS of 19.8 months versus 17.4 months; HR, 0.87; 95\% CI, 0.77-0.99; p=0.039). Survival data will not be mature until 2013 (Kristensen et al., 2011).

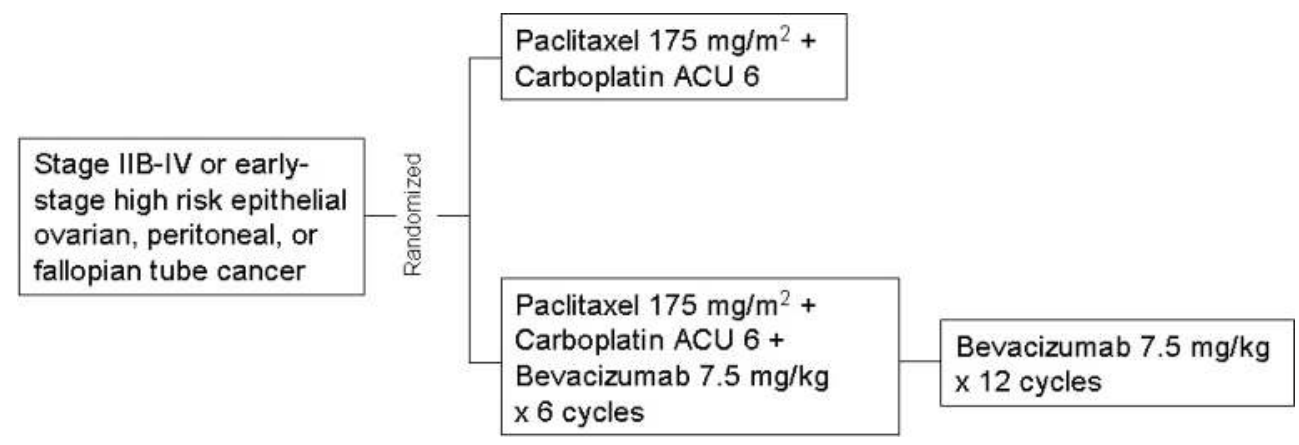

Fig. 4. ICON7 schema.

The last trial is GOG252 (NCT00951496), which will not determine the efficacy of additional bevacizumab, but rather is designed to compare intravenous versus intraperitoneal carboplatin, and intraperitoneal carboplatin versus intraperitoneal cisplatin plus paclitaxel in the setting of front-line therapy. All participants received bevacizumab in the front-line setting as well as bevacizumab consolidation chemotherapy (Figure 5). 


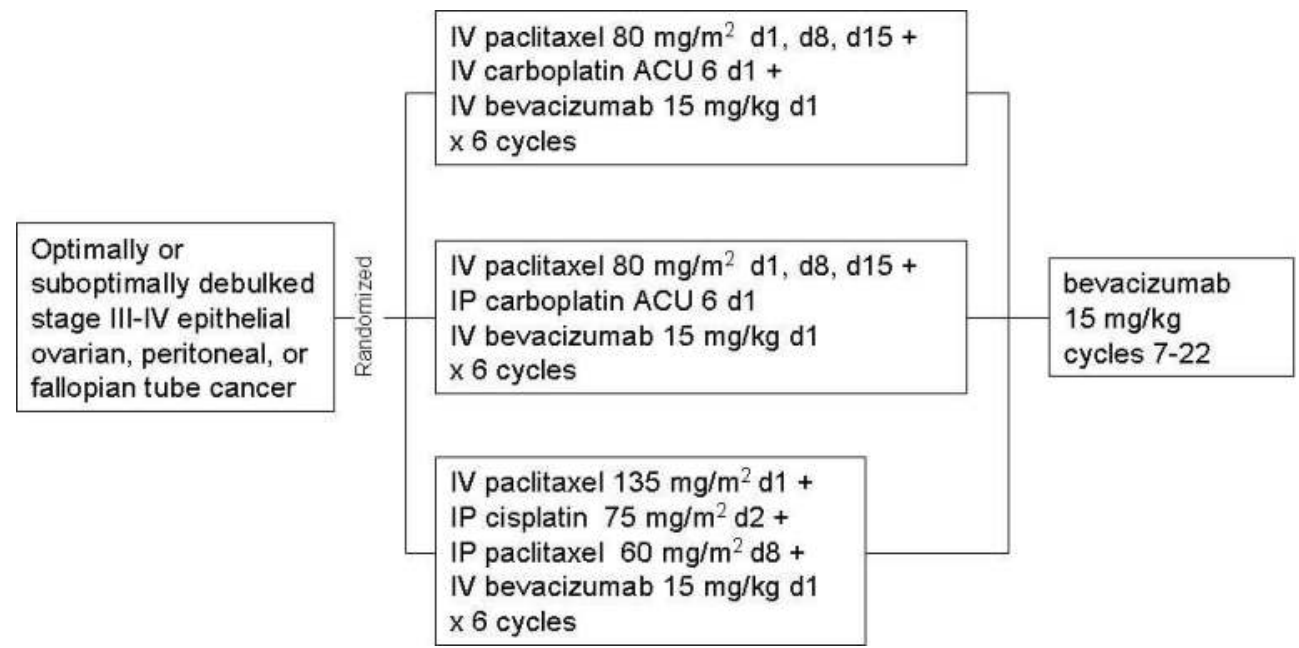

Fig. 5. GOG 252 schema.

The activity of bevacizumab in patients with recurrent ovarian cancer is currently being evaluated in several phase III trials. GOG 213 (NCT00565851) was designed to evaluate the roles of secondary cytoreductive surgery and bevacizumab in combination with carboplatinpaclitaxel in patients with platinum-sensitive recurrent ovarian cancer (Figure 6).

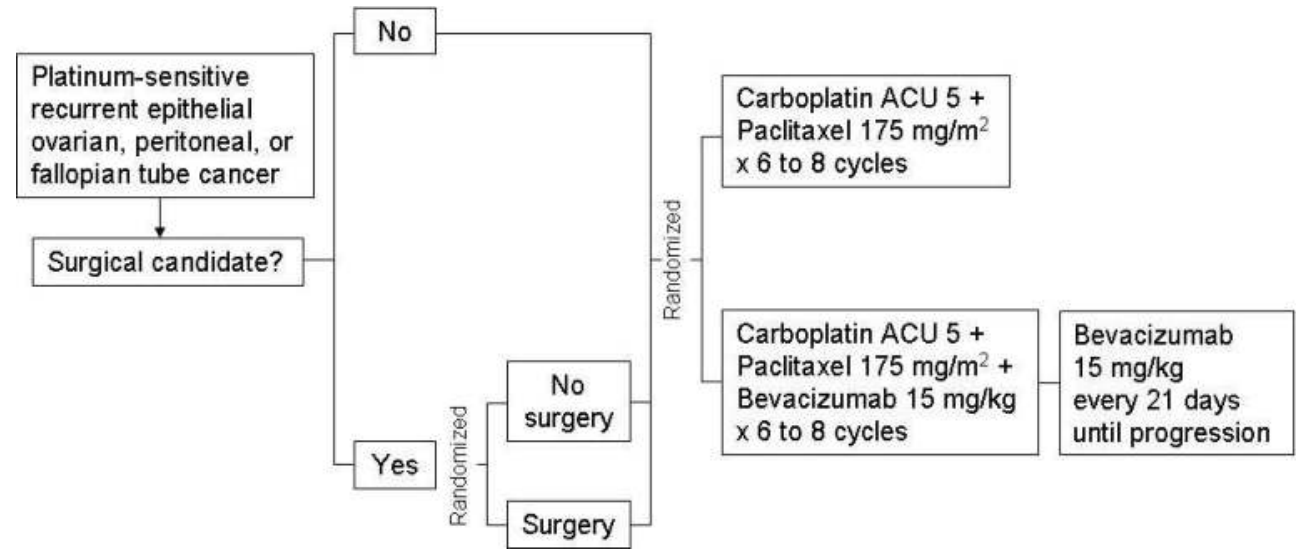

Fig. 6. GOG 213 schema.

The Ovarian Cancer Evaluation of Avastin and Safety-AVF4095g trial (OCEANS) is a phase III study designed to compare gemcitabine and carboplatin with or without bevacizumab in patients with platinum-sensitive recurrent ovarian, primary peritoneal, or fallopian tube cancer (NCT00434642). After 6 cycles of combination chemotherapy with carboplatingemcitabine, the patients will continue to receive bevacizumab or placebo consolidation therapy for up to 51 weeks (Figure 7). After a median follow-up period of 24 months, preliminary results from 484 patients were presented at the 2011 meeting of the ASCO 
(Aghajanian et al., 2011). Patients treated with concurrent and maintenance bevacizumab showed significantly longer PFS compared to the standard chemotherapy arm (12.4 months versus 8.4 months; hazard ratio, $0.484 ; 95 \% \mathrm{Cl}, 0.388-0.605 ; \mathrm{p}<0.0001)$. The survival data are not mature.

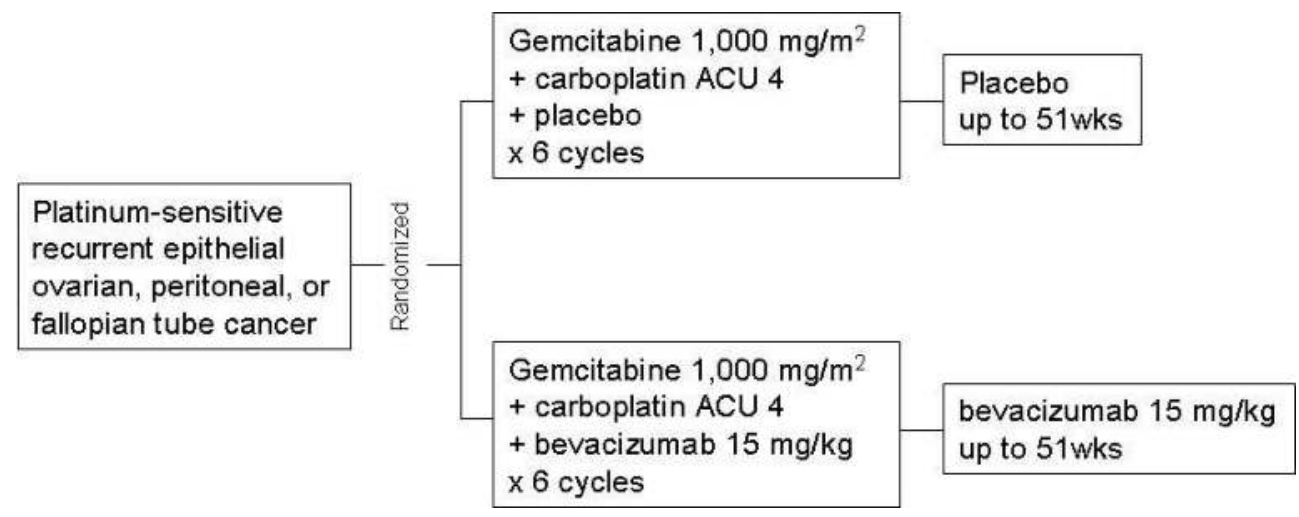

Fig. 7. OCEANS schema.

The AURELIA study (NCT00976911) is a phase III study designed to evaluate the benefit of adding bevacizumab to standard chemotherapy in patients with recurrent epithelial ovarian, fallopian tube, or primary peritoneal cancer who displayed disease progression within 6 months of platinum therapy. The patients will receive paclitaxel, topotecan, or liposomal doxorubicin with or without concomitant bevacizumab (Figure 8).

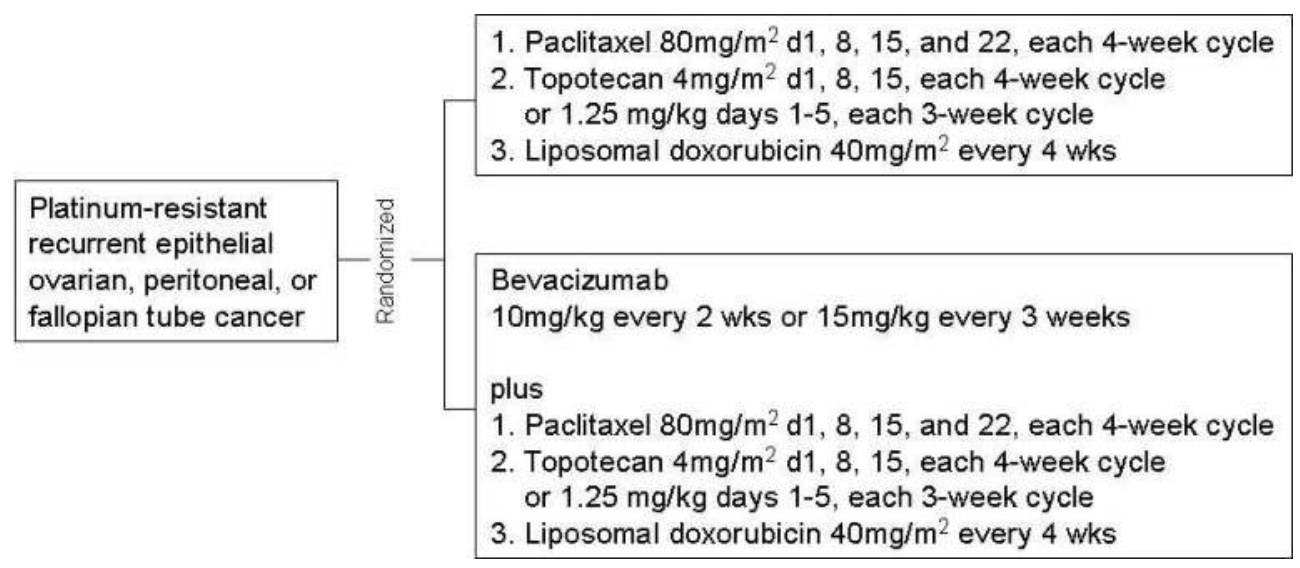

Fig. 8. AURELIA schema.

\subsubsection{Bevacizumab for palliative treatment}

The ability of bevacizumab as a palliative agent for symptomatic ascites has also been evaluated in several studies. In a report by Numnum et al, treatment with bevacizumab for 
patients with recurrent ovarian cancer with symptomatic ascites resulted in relief of symptoms associated with ascites formation. Moreover, objectively, no patient required a paracentesis after the initiation of bevacizumab therapy (Numnum et al., 2006). These results suggest that it is reasonable to consider the use of bevacizumab as a palliative agent in patients with end stage ovarian cancer with symptomatic ascites.

\subsection{Aflibercept (AVE0005/VEGF trap)}

Aflibercept (AVE0005/VEGF trap) is a fusion protein that inactivates VEGF by acting as a decoy receptor for VEGF, preventing VEGF binding to VEGFR. Preclinical in vivo studies have demonstrated that treatment with aflibercept resulted in a decreased tumor burden and reduced ascites formation as a result of tumor angiogenesis inhibition (Byrne et al., 2003).

The clinical activity of aflibercept in ovarian cancer has been evaluated in several phase I/II studies (Moroney et al., 2009). In a randomized, double-blind, phase II study of patients with recurrent ovarian cancer, aflibercept produced a significant tumor response (according to the RECIST criteria) or CA-125 response (defined as a 50\% reduction in the CA-125 protein level) was observed in $18(13.8 \%)$ out of 130 evaluable patients. In addition, of the 40 patients who had evaluable ascites at the baseline, $77.5 \%$ demonstrated the complete disappearance or stabilization of their ascites (Tew et al., 2007).

On the basis of the promising results from these preclinical and clinical investigations, aflibercept has been evaluated in a phase III trial (Table 2). In this trial, the effect of aflibercept on the necessity of repeated paracentesis for symptomatic ascites in patients with advanced ovarian cancer has been evaluated (NCT00327444) (Figure 9).

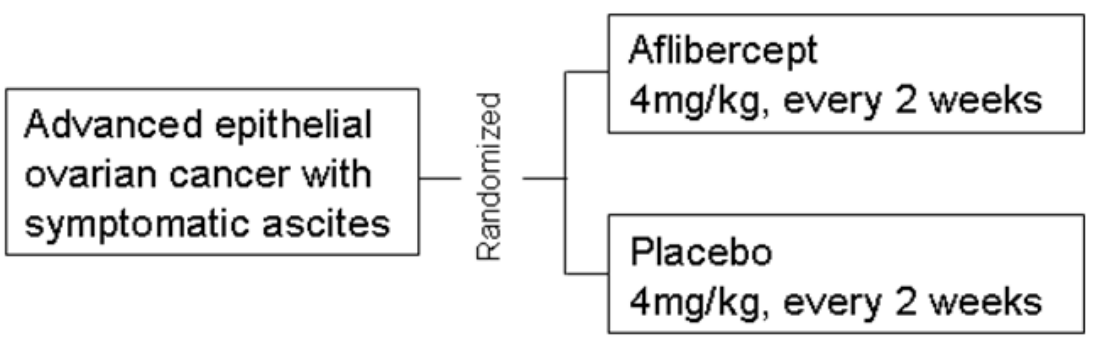

Fig. 9. NCT00327444 schema.

\subsection{Tyrosine kinase inhibitors}

Another strategy is the inhibition of the VEGF receptor using tyrosine kinase inhibitors (Teoh \& Secord, 2011). In contrast to the specific inhibition of the VEGF pathway using bevacizumab or aflibercept, most TKI target multiple receptors responsible for tumorangiogenesis. Theoretically, these multi-targeting anti-angiogenic agents inhibit tumor angiogenesis more completely than agents that specifically target VEGF, and thus, might have a greater therapeutic benefit. Several TKI have demonstrated clinical activity in phase I/II trials involving patients with ovarian cancer and are currently being evaluated in phase III trials (Table 2). 


\begin{tabular}{|c|c|c|c|c|c|}
\hline Compound & Target & Setting & Patients & Endopoint & Status \\
\hline Aflibercept & VEGF & Recurrent & $\begin{array}{l}\text { Arm 1: Placebo } \\
\text { Arm 2: Aflibercept }\end{array}$ & $\begin{array}{l}\text { Time to } \\
\text { repeat } \\
\text { para- } \\
\text { centesis }\end{array}$ & $\begin{array}{l}\text { Completed } \\
\text { Results } \\
\text { not yet } \\
\text { available }\end{array}$ \\
\hline Cediranib & $\begin{array}{l}\text { VEGFR } \\
-1,2,3 \\
\text { PDGFR } \\
-\beta \\
\text { c-kit }\end{array}$ & Recurrent & $\begin{array}{l}\text { Arm 1: CT } \\
\text { Arm 2: CT+Ced } \\
\text { Arm 3: CT+Ced+ } \\
\text { maintenance Ced }\end{array}$ & $\begin{array}{l}\text { PFS and } \\
\text { OS }\end{array}$ & $\begin{array}{l}\text { Open to } \\
\text { accrual }\end{array}$ \\
\hline Pazopanib & $\begin{array}{l}\text { VEGFR } \\
-1,2,3 \\
\text { PDGFR } \\
-\alpha, \beta \\
\text { c-kit }\end{array}$ & Maintenance* & $\begin{array}{l}\text { Arm 1: Placebo } \\
\text { Arm 2: Pazopanib }\end{array}$ & PFS & $\begin{array}{l}\text { Completed } \\
\text { accrual }\end{array}$ \\
\hline BIBF 1120 & $\begin{array}{l}\text { VEGFR } \\
-1,2,3 \\
\text { PDGFR } \\
-\alpha, \beta \\
\text { FGFR- } \\
1,2,3\end{array}$ & $\begin{array}{l}\text { Front-line } \\
\text { adjuvant }\end{array}$ & $\begin{array}{l}\text { Arm 1: CT } \\
\text { Arm 2: CT+BIBF } \\
1120\end{array}$ & PFS & $\begin{array}{l}\text { Open to } \\
\text { accrual }\end{array}$ \\
\hline
\end{tabular}

Table 2. Summary of the randomized controlled trials evaluating the efficacy of tyrosine kinase inhibitors against ovarian cancer. Ced, Cediranib; PFS, progression free survival; OS, overall survival.

* Maintenance treatment for patients whose cancer had not progressed during first line chemotherapy.

\subsubsection{Cediranib}

Cediranib is an oral TKI that targets all three VEGFR, PDGFR, and c-kit. In the setting of a phase II study of patients with recurrent epithelial ovarian cancer or fallopian tube cancer, cediranib demonstrated significant clinical activity. In this trial, single agent cediranib showed a clinical benefit rate (complete response, partial response, stable disease, or CA125 non-progression) of 30\% (Matulonis et al., 2009).

Cediranib is currently being evaluated in a phase III trial (ICON6), which was designed to investigate the clinical benefit of adding cediranib to carboplatin-paclitaxel, as well as the benefit of continuing cediranib as a maintenance therapy in patients with platinumsensitive, recurrent ovarian cancer (NCT00532194) (Figure 10). 


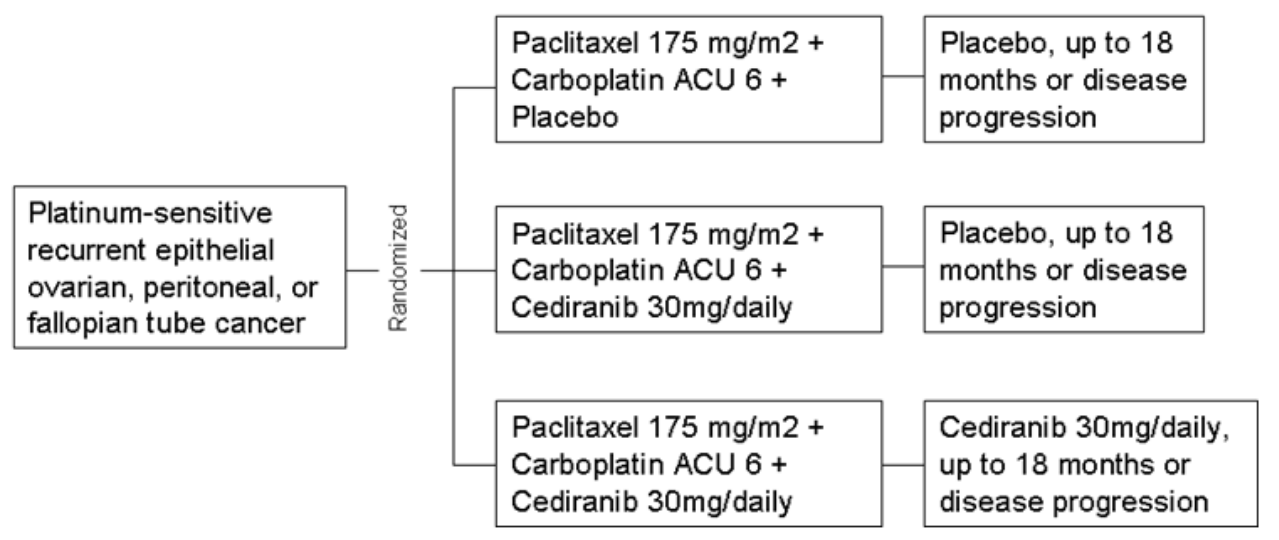

Fig. 10. NCT00532194 schema.

\subsubsection{Pazopanib}

Pazopanib, an oral TKI that targets all three VEGFR, PDGFR, and c-kit, was approved by the United States Food and Drug Administration in 2009 for the treatment of patients with advanced renal cell carcinoma. The clinical activity of pazopanib in ovarian cancer has been evaluated in several phase I/II trials (Monk et al., 2010; Friedlander et al., 2010). In a phase II trial in which the CA-125 response ( $\geq 50 \%$ decrease from baseline) was the primary endpoint, pazopanib demonstrated a CA-125 response rate of $31 \%$ (11 out of 36 patients). In 17 patients with measurable disease, the overall response rate (according to the RECIST criteria) was $18 \%$.

On the basis of these results, the activity of pazopanib is currently being evaluated in a phase III study, which was designed to compare the efficacy of pazopanib versus placebo in women whose disease had not progressed after first-line chemotherapy for epithelial ovarian, fallopian tube, or primary peritoneal cancer (NCT00866697) (Figure 11).

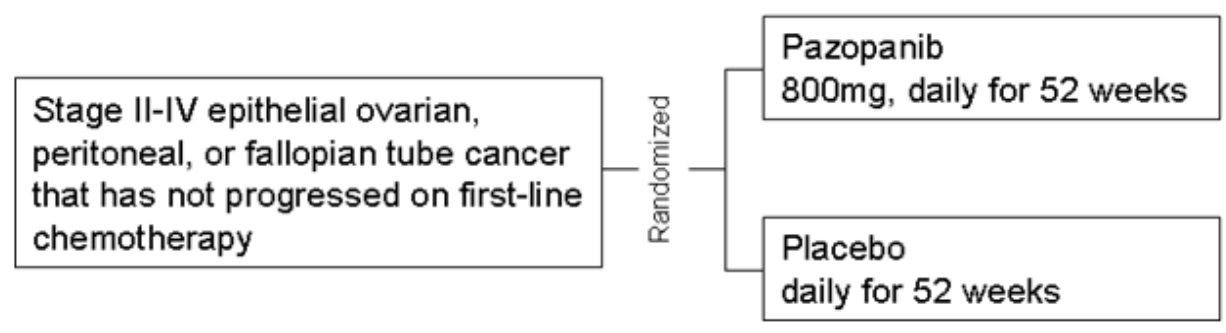

Fig. 11. NCT00866697 schema.

\subsubsection{BIBF 1120}

BIBF 1120 is an orally available TKI that binds and inhibits VEGFR, PDGFR, and FGFR tyrosine kinases. On the basis of a promising randomized controlled phase II trial highlighting the benefit of maintenance treatment with BIBF 1120 after salvage chemotherapy in patients with recurrent ovarian cancer (Ledermann et al., 2009), the 
Arbeitsgemeinschaft Gynakologische Oncologie (AGO) is currently conducting a Phase III trial (AGO-OVAR-12). This trial was designed to evaluate the efficacy of BIBF 1120 in combination with carboplatin-paclitaxel in patients with advanced epithelial ovarian cancer in the setting of front-line treatment (NCT01015118) (Figure 12).

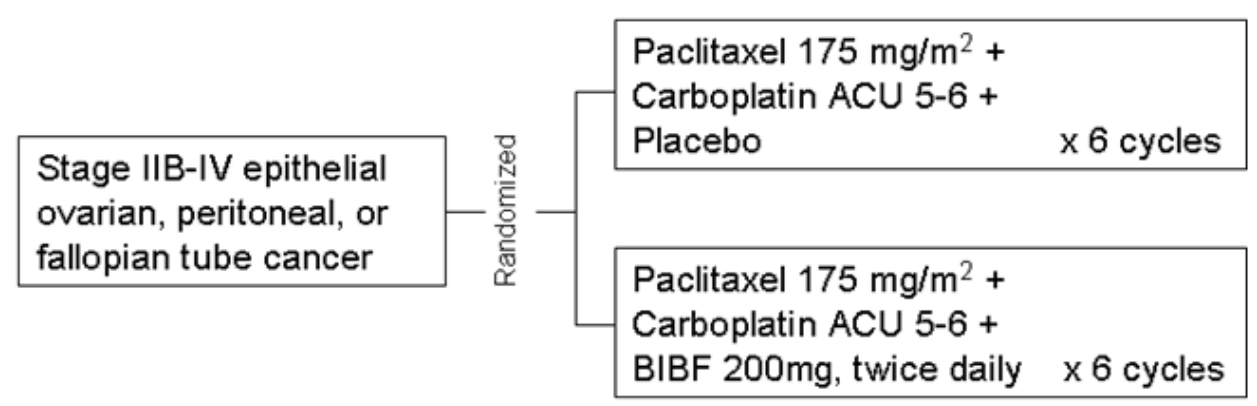

Fig. 12. NCT01015118 schema.

\section{Toxic effects of VEGF-targeting agents}

As VEGF mediates physiologically important processes in healthy tissues, VEGF-targeting agents are associated with unique and potentially problematic side effects (Stone et al., 2010).

Hypertension is the most common side effect of VEGF-targeting agents. It typically occurs within 3 weeks of the beginning of therapy. The pathogenesis of hypertension associated with VEGF-targeting agents is not fully understood. However, it is speculated that the suppression of nitric oxide production by VEGF antagonism leads to vasoconstriction and decreased sodium ion renal excretion, which results in elevated blood pressure (Izzedine et al., 2009). A recent review of the adverse effects of anti-angiogenic therapies suggested that the incidence of grade $3 / 4$ hypertension in patients that had been treated with bevacizumab, aflibercept, or TKI was $8-26 \%, 9-32 \%$, and 5-48\%, respectively (Stone et al., 2010).

Proteinuria is another common side effect observed in patients treated with bevacizumab or aflibercept. In clinical trials of bevacizumab or aflibercept, grade 3/4 proteinuria occurred in approximately 1-4\% of patients (Izzedine et al., 2010). Proteinuria is rare in patients treated with TKI. Such proteinuria is reported to occur as a result of the disruption of VEGFdependent glomerular endothelial integrity (Ostendorf et al., 1999).

Wound healing complications is another serious side effect that is reported to occur in patients treated with VEGF-targeting agents. As the wound-healing process is dependent on angiogenesis, VEGF-targeting agents have the potential to delay the wound-healing process in patients who undergo surgery. On the basis of a previous report suggesting that patients who undergo surgery within 28-60 days of bevacizumab therapy are at an increased risk of wound-healing complications, physicians recommend avoiding major surgery at least 30 days after the completion of bevacizumab treatment (Shord et al., 2009).

The increased risk of atrial thromboembolic events (ATE), usually myocardial or cerebrovascular events, is another serious adverse effect associated with bevacizumab 
therapy. In a recent analysis of 1745 patients with colorectal, breast, or non-small-cell lung cancer from five randomized trials, the addition of bevacizumab to chemotherapy was associated with an increased risk of ATE (incidence of $3.8 \%$ in the combination therapy group vs $1.7 \%$ in the chemotherapy alone group) (Scappaticci et al., 2007). The precise incidence of ATE in patients with ovarian cancer who have been treated with VEGFtargeting agents is unknown; however, so far, 30 ATE events have been reported. ATE events are rarely reported in patients who have been treated with aflibercept or TKI (Stone et al., 2010).

The most serious complication of VEGF-targeting agents is bowel perforation. In a recent review of 9 clinical studies examining the use of bevacizumab in ovarian cancer patients, the overall frequency of bowel perforation was $5.4 \%$, which was higher than the $2.4 \%$ observed in patients with colorectal cancer (Han \& Monk, 2007). Bowel perforation was also observed in patients that had been treated with aflibercept (Colombo et al., 2008), however, there have been no reported cases of bowel perforation involving patients that were treated with TKI monotherapy (Stone et al., 2010). The management of bowel perforation is difficult because of the increased likelihood of surgical and postoperative complications, such as thrombosis or compromised wound healing caused by bevacizumab treatment, suggesting the importance of preventing this serious complication. The precise mechanisms of, and risk factors for, bowel perforation are largely unknown. However, Simpkins et al. suggested from their experience that bowel perforation can be avoided by carefully selecting patients without clinical symptoms of bowel obstruction, evidence of rectosigmoid involvement on a pelvic examination, or evidence of bowel involvement on a computed tomography (CT) scan (Simpkins et al., 2007).

At this point, no standard recommendations exist for the management of the adverse effects induced by VEGF-targeting agents. Further investigations are needed to solve this issue.

\section{Conclusions and future directions}

Recent increases in our understanding of cancer biology and the molecular pathways that control tumor angiogenesis have led to the identification of novel VEGF-targeting agents that can be used to treat ovarian cancer. Although VEGF-targeting agents have yielded promising results in ovarian cancer in the settings of front-line treatment and salvage treatment, several important clinical issues remain unanswered. The optimal methods for evaluating the efficacy of VEGF-targeting agents have yet to be clarified. As VEGFtargeting agents have cytostatic rather than cytotoxic effects, the traditional criteria applied to cytotoxic agents, such as the RECIST criteria, might be less applicable. The identification of surrogate biomarkers that can be used to guide drug choice or optimal dosing or to predict the tumor response or drug resistance is of paramount importance. In addition, increased understanding of the mechanisms underlying the unique toxic effects of VEFG-targeting agents, as well as the development of evidence-based management strategies for these adverse effects, are also necessary. Choosing the optimal VEGFtargeting agent for each patient will extend patient survival without reducing quality of life in the near future.

\section{Acknowledgement}

We thank Remina Emoto for providing secretarial assistance. 


\section{References}

Aghajanian, C., Finkler, NJ., Rutherford, T. et al., OCEANS: A randomized, double-blinded, placebo-controlled phase III trial of chemotherapy with or without bevacizumab $(B E V)$ in patients with platinum-sensitive recurrent epithelial ovarian (EOC), primary peritoneal (PPC), or fallopian tube cancer (FTC), Presented at: the 47th Annual Meeting of the American Society of Clinical Oncology; Chicago, IL, USA (June, 2011).

Brustmann, H. Vascular endothelial growth factor expression in serous ovarian carcinoma: relationship with topoisomerase II alpha and prognosis. Gynecol Oncol 2004;95:1622.

Burger, RA., Sill, MW., Monk, BJ., Greer, BE., \& Sorosk, JI. Phase II trial of bevacizumab in persistent or recurrent epithelial ovarian cancer or primary peritoneal cancer: a Gynecologic Oncology Group Study. J Clin Oncol 2007; 25:5165-5171.

Burger, RA., Brady, MF. Bookman, MA. et al., Phase III trial of bevacizumab (BEV) in the primary treatment of advanced epithelial ovarian cancer (EOC), primary peritoneal cancer (PPC), or fallopian tube cancer (FTC): a gynecologic oncology group study, Presented at: the 46th Annual Meeting of the American Society of Clinical Oncology; Chicago, IL, USA (June, 2010).

Burger, RA. Overview of anti-angiogenic agents in development for ovarian cancer. Gynecol Oncol. 2011;121:230-238.

Byrne, AT., Ross, L., Holash, J., Nakanishi, M., Hu, L., Hofmann, JI., Yancopoulos, GD., \& Jaffe, RB. Vascular endothelial growth factor-trap decreases tumor burden, inhibits ascites, and causes dramatic vascular remodeling in an ovarian cancer model. Clin Cancer Res. 2003;9:5721-5728.

Cannistra, SA., Matulonis, UA., Penson, RT., Hambleton, J., Dupont, J., Mackey, H., Douglas, J., Burger, RA., Armstrong, D., Wenham, R., \& McGuire, W. Phase II study of bevacizumab in patients with platinum-resistant ovarian cancer or peritoneal serous cancer. J Clin Oncol 2007;25:5180-5186.

Carmeliet, P. Mechanisms of angiogenesis and arteriogenesis. Nat Med. 2000;6:389-395.

Colombo, N., Mangili, G., Mammoliti, S. et al., Aflibercept (VEGF Trap) for advanced epithelial ovarian cancer (EOC) patients (pts) with symptomatic malignant ascites: Preliminary results of a pilot study, Presented at: the 44th Annual Meeting of the American Society of Clinical Oncology; Chicago, IL, USA (June, 2008).

Cooper, BC., Ritchie, JM., Broghammer, CL., Coffin, J., Sorosky, JI., Buller, RE., Hendrix, MJ., \& Sood, AK.Preoperative serum vascular endothelial growth factor levels: significance in ovarian cancer. Clin Cancer Res. 2002;8:3193-3197.

Eskander, RN., \& Randall, LM. Bevacizumab in the treatment of ovarian cancer. Biologics. 2011;5:1-5.

Ferrara, N. VEGF and the quest for tumour angiogenesis factors. Nat Rev Cancer 2002;2:795803.

Ferrara, N., \& Kerbel RS. Angiogenesis as a therapeutic target. Nature. 2005;438:967-974.

Forsythe, JA., Jiang, BH., Iyer, NV., Agani, F., Leung, SW., Koos, RD., \& Semenza, GL. Activation of vascular endothelial growth factor gene transcription by hypoxiainducible factor 1. Mol Cell Biol. 1996;16:4604-4613. 
Friedlander, M., Hancock, KC., Rischin, D., Messing, MJ., Stringer, CA., Matthys, GM., Ma, B., Hodge, JP., \& Lager, JJ. A Phase II, open-label study evaluating pazopanib in patients with recurrent ovarian cancer. Gynecol Oncol. 2010;119:32-37.

Garcia, AA., Hirte, H., Fleming, G., Yang, D., Tsao-Wei, DD., Roman, L., Groshen, S., Swenson, S., Markland, F., Gandara, D., Scudder, S., Morgan, R., Chen, H., Lenz, HJ., \& Oza, AM. Phase II clinical trial of bevacizumab and low-dose metronomic oral cyclophosphamide in recurrent ovarian cancer: a trial of the California, Chicago, and Princess Margaret Hospital phase II consortia. J Clin Oncol 2008; 26:76-82.

Gerber, HP., \& Ferrara, N. Pharmacology and pharmacodynamics of bevacizumab as monotherapy or in combination with cytotoxic therapy in preclinical studies. Cancer Res. 2005;65:671-680.

Gimbrone, MA. Jr., Leapman, SB., Cotran, RS., \& Folkman, J. Tumor dormancy in vivo by prevention of neovascularization. J Exp Med 1972;136:261-276.

Han, ES., Monk, \& BJ. What is the risk of bowel perforation associated with bevacizumab therapy in ovarian cancer? Gynecol Oncol. 2007;105:3-6.

Hefler, LA., Zeillinger, R., Grimm, C., Sood, AK., Cheng, WF., Gadducci, A., Tempfer, CB., \& Reinthaller, A. Preoperative serum vascular endothelial growth factor as a prognostic parameter in ovarian cancer. Gynecol Oncol. 2006;103:512-517.

Hu, L., Hofmann, J., Zaloudek, C., Ferrara, N., Hamilton, T., \& Jaffe, RB. Vascular endothelial growth factor immunoneutralization plus Paclitaxel markedly reduces tumor burden and ascites in athymic mouse model of ovarian cancer. Am J Pathol. 2002;161:1917-1924.

Izzedine, H., Ederhy, S., Goldwasser, F., Soria, JC., Milano, G., Cohen, A., Khayat, D., \& Spano, JP. Management of hypertension in angiogenesis inhibitor-treated patients. Ann Oncol. 2009;20:807-815.

Izzedine, H., Massard, C., Spano, JP., Goldwasser, F., Khayat, D., \& Soria, JC. VEGF signalling inhibition-induced proteinuria: Mechanisms, significance and management. Eur J Cancer. 2010;46:439-448.

Jain, RK. Normalization of tumor vasculature: an emerging concept in antiangiogenic therapy. Science 2005;307:58-62.

Karkkainen, MJ., Saaristo, A., Jussila, L., Karila, KA., Lawrence, EC., Pajusola, K., Bueler, H., Eichmann, A., Kauppinen, R., Kettunen, MI., Yla-Herttuala, S., Finegold, DN., Ferrell, RE., \& Alitalo K. A model for gene therapy of human hereditary lymphedema. Proc Natl Acad Sci U S A. 2001;98:12677-12682.

Kerbel, RS. Inhibition of tumor angiogenesis as a strategy to circumvent acquired resistance to anti-cancer therapeutic agents. Bioessays. 1991;13:31-36.

Kristensen, G., Perren, T., Qian, W. et al., Result of interim analysis of overall survival in the GCIG ICON7 phase III randomized trial of bevacizumab in women with newly diagnosed ovarian cancer, Presented at: the 47th Annual Meeting of the American Society of Clinical Oncology; Chicago, IL, USA (June, 2011)

Ledermann, JA., Rustin, GJ., Hackshaw, A. et al., A randomised phase II placebo-controlled trial using maintenance therapy to evaluate the vascular targeting agent BIBF 1120 following treatment of relapsed ovarian cancer, Presented at: the 16th Biennial International Meeting of the European Society of Gynaecological Oncology; Belgrade, Serbia (October, 2009). 
Li, L., Wang, L., Zhang, W., Tang, B., Zhang, J., Song, H., Yao, D., Tang, Y., Chen, X., Yang, Z., Wang, G., Li, X., Zhao, J., Ding, H., Reed, E., \& Li, QQ. Correlation of serum VEGF levels with clinical stage, therapy efficacy, tumor metastasis and patient survival in ovarian cancer. Anticancer Res. 2004;24:1973-1979.

Mabuchi, S., Terai, Y., Morishige, K., Tanabe-Kimura, A., Sasaki, H., Kanemura, M., Tsunetoh, S., Tanaka, Y., Sakata, M., Burger, RA., Kimura, T., \& Ohmichi, M. Maintenance treatment with bevacizumab prolongs survival in an in vivo ovarian cancer model. Clin Cancer Res 2008;14:7781-7789.

Mabuchi, S., Kawase, C., Altomare, DA., Morishige, K., Hayashi, M., Sawada, K., Ito, K., Terai, Y., Nishio, Y., Klein-Szanto, AJ., Burger, RA., Ohmichi, M., Testa, JR., \& Kimura, T. Vascular endothelial growth factor is a promising therapeutic target for the treatment of clear cell carcinoma of the ovary. Mol Cancer Ther. 2010a;9:24112422.

Mabuchi, S., Morishige, K., \& Kimura, T. Use of monoclonal antibodies in the treatment of ovarian cancer. Curr Opin Obstet Gynecol. 2010b;22:3-8.

Matulonis, UA., Berlin, S., Ivy, P., Tyburski, K., Krasner, C., Zarwan, C., Berkenblit, A., Campos, S., Horowitz, N., Cannistra, SA., Lee, H., Lee, J., Roche, M., Hill, M., Whalen, C., Sullivan, L., Tran, C., Humphreys, BD., \& Penson, RT. Cediranib, an oral inhibitor of vascular endothelial growth factor receptor kinases, is an active drug in recurrent epithelial ovarian, fallopian tube, and peritoneal cancer. J Clin Oncol. 2009;27:5601-5606.

Mesiano, S., Ferrara, N., \& Jaffe, RB. Role of vascular endothelial growth factor in ovarian cancer: inhibition of ascites formation by immunoneutralization. Am J Pathol. 1998;153:1249-1256.

Monk, BJ., Mas Lopez, L., Zarba, JJ., Oaknin, A., Tarpin, C., Termrungruanglert, W., Alber, JA., Ding, J., Stutts, MW., \& Pandite, LN. Phase II, open-label study of pazopanib or lapatinib monotherapy compared with pazopanib plus lapatinib combination therapy in patients with advanced and recurrent cervical cancer. J Clin Oncol. 2010;28:3562-3569.

Moroney, JW., Sood, AK., \& Coleman, RL. Aflibercept in epithelial ovarian carcinoma. Future Oncol. 2009;5:591-600.

Numnum, TM., Rocconi, RP., Whitworth, J., \& Barnes, MN. The use of bevacizumab to palliate symptomatic ascites in patients with refractory ovarian carcinoma. Gynecol Oncol 2006;102:425-428.

Ostendorf, T., Kunter, U., Eitner, F., Loos, A., Regele, H., Kerjaschki, D., Henninger, DD., Janjic, N., \& Floege, J. VEGF(165) mediates glomerular endothelial repair. J Clin Invest. 1999;104:913-923.

Penson, RT., Dizon, DS., Cannistra, SA., Roche, MR., Krasner, CN., Berlin, ST., Horowitz, NS., Disilvestro, PA., Matulonis, UA., Lee, H., King, MA., \& Campos, SM. Phase II study of carboplatin, paclitaxel, and bevacizumab with maintenance bevacizumab as first-line chemotherapy for advanced mullerian tumors. J Clin Oncol 2010;28:154-159.

Perren, T. et al., ICON7: A phase III randomized gynecologic cancer intergroup trial of concurrent bevacizumab and chemotherapy followed by maintenance bevacizumab, versus chemotherapy alone in women with newly diagnosed epithelial ovarian (EOC), primary peritoneal (PPC), or fallopian tube cancer (FTC), 
Presented at: the 35th European Society of Medical Oncology meeting; Milan, Italy (October, 2010).

Presta, LG., Chen, H., O'Connor, SJ., Chisholm, V., Meng, YG., Krummen, L., Winkler, M., \& Ferrara, N. Humanization of an anti-vascular endothelial growth factor monoclonal antibody for the therapy of solid tumors and other disorders. Cancer Res. 1997;57:4593-4599.

Rafii, S., Lyden, D., Benezra, R., Hattori, K., \& Heissig, B. Vascular and haematopoietic stem cells: novel targets for anti-angiogenesis therapy? Nat Rev Cancer. 2002;2:826-835.

Schönau, KK., Steger, GG., \& Mader, RM. Angiogenic effect of naive and 5-fluorouracil resistant colon carcinoma on endothelial cells in vitro. Cancer Lett 2007;257:73-78.

Scappaticci, FA., Skillings, JR., Holden, SN., Gerber, HP., Miller, K., Kabbinavar, F., Bergsland, E., Ngai, J., Holmgren, E., Wang, J., \& Hurwitz, H. Arterial thromboembolic events in patients with metastatic carcinoma treated with chemotherapy and bevacizumab. J Natl Cancer Inst. 2007;99:1232-1239.

Senger, DR., Galli, SJ., Dvorak, AM., Perruzzi, CA., Harvey, VS., \& Dvorak, HF. Tumor cells secrete a vascular permeability factor that promotes accumulation of ascites fluid. Science 1983;219: 983-985.

Shord, SS., Bressler, LR., Tierney, LA., Cuellar, S., \& George, A. Understanding and managing the possible adverse effects associated with bevacizumab. Am J Health Syst Pharm. 2009;66:999-1013.

Simpkins, F., Belinson, JL., Rose, \& PG. Avoiding bevacizumab related gastrointestinal toxicity for recurrent ovarian cancer by careful patient screening. Gynecol Oncol. 2007;107:118-123.

Sood, AK., Seftor, EA., Fletcher, MS., Gardner, LM., Heidger, PM., Buller, RE., Seftor, RE., \& Hendrix, MJ. Molecular determinants of ovarian cancer plasticity. Am J Pathol. 2001;158:1279-1288.

Spannuth, WA., Sood, AK., \& Coleman, RL. Angiogenesis as a strategic target for ovarian cancer therapy. Nat Clin Pract Oncol. 2008;5:194-204.

Spannuth, WA., Nick, AM., Jennings, NB., Armaiz-Pena, GN., Mangala, LS., Danes, CG., Lin, YG., Merritt, WM., Thaker, PH., Kamat, AA., Han, LY., Tonra, JR., Coleman, RL., Ellis, LM., \& Sood AK. Functional significance of VEGFR-2 on ovarian cancer cells. Int J Cancer. 2009;124:1045-1053.

Stone, RL., Sood, AK., \& Coleman, RL. Collateral damage: toxic effects of targeted antiangiogenic therapies in ovarian cancer. Lancet Oncol. 2010;11:465-475.

Teoh, DG., \& Secord, AA. Antiangiogenic therapies in epithelial ovarian cancer. Cancer Control. 2011;18:31-43.

Tew, WP., Colombo, N., Ray-Coquard, I. et al., VEGF-Trap for patients (pts) with recurrent platinum-resistant epithelial ovarian cancer (EOC): preliminary results of a randomized, multicenter phase II study, Presented at: the 43th Annual Meeting of the American Society of Clinical Oncology; Chicago, IL, USA (June, 2007).

Wong, C., Wellman, TL., \& Lounsbury, KM. VEGF and HIF-1alpha expression are increased in advanced stages of epithelial ovarian cancer. Gynecol Oncol 2003;91: 513-517. 
Yamamoto, S., Konishi, I., Mandai, M., Kuroda, H., Komatsu, T., Nanbu, K., Sakahara, H., \& Mori, T. Expression of vascular endothelial growth factor (VEGF) in epithelial ovarian neoplasms: correlation with clinicopathology and patient survival, and analysis of serum VEGF levels. Br J Cancer 1997;76:1221-1227.

Zhang, L., Yang, N., Garcia, JR., Mohamed, A., Benencia, F., Rubin, SC., Allman, D., \& Coukos, G. Generation of a syngeneic mouse model to study the effects of vascular endothelial growth factor in ovarian carcinoma. Am J Pathol 2002;161:2295-309. 


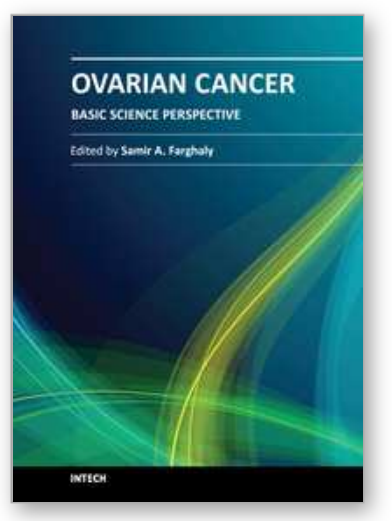

\author{
Ovarian Cancer - Basic Science Perspective \\ Edited by Dr. Samir Farghaly
}

ISBN 978-953-307-812-0

Hard cover, 406 pages

Publisher InTech

Published online 17, February, 2012

Published in print edition February, 2012

Worldwide, Ovarian carcinoma continues to be responsible for more deaths than all other gynecologic malignancies combined. International leaders in the field address the critical biologic and basic science issues relevant to the disease. The book details the molecular biological aspects of ovarian cancer. It provides molecular biology techniques of understanding this cancer. The techniques are designed to determine tumor genetics, expression, and protein function, and to elucidate the genetic mechanisms by which gene and immunotherapies may be perfected. It provides an analysis of current research into aspects of malignant transformation, growth control, and metastasis. A comprehensive spectrum of topics is covered providing up to date information on scientific discoveries and management considerations.

\title{
How to reference
}

In order to correctly reference this scholarly work, feel free to copy and paste the following:

Seiji Mabuchi, Atsuko Wakabayashi and Tadashi Kimura (2012). VEGF Targeting Agents in Ovarian Cancer, Ovarian Cancer - Basic Science Perspective, Dr. Samir Farghaly (Ed.), ISBN: 978-953-307-812-0, InTech, Available from: http://www.intechopen.com/books/ovarian-cancer-basic-science-perspective/vegf-targetingtherapy-in-ovarian-cancer

\section{INTECH}

open science | open minds

\section{InTech Europe}

University Campus STeP Ri

Slavka Krautzeka 83/A

51000 Rijeka, Croatia

Phone: +385 (51) 770447

Fax: +385 (51) 686166

www.intechopen.com

\section{InTech China}

Unit 405, Office Block, Hotel Equatorial Shanghai

No.65, Yan An Road (West), Shanghai, 200040, China 中国上海市延安西路65号上海国际贵都大饭店办公楼 405 单元

Phone: +86-21-62489820

Fax: $+86-21-62489821$ 
(C) 2012 The Author(s). Licensee IntechOpen. This is an open access article distributed under the terms of the Creative Commons Attribution 3.0 License, which permits unrestricted use, distribution, and reproduction in any medium, provided the original work is properly cited. 